\title{
Psychiatry of Radicalization and Terrorism in the Lone Wolf, Children, and Women: An E-ethnographic Approach for Analysis
}

\author{
Carlo Lazzari ${ }^{1, ~ *}$, Abdul Nusair ${ }^{1}$, Marco Rabottini ${ }^{2}$ \\ ${ }^{1}$ Department of Psychiatry, South-west Yorkshire Trust, Wakefield, United Kingdom \\ ${ }^{2}$ Department Psychiatry, International Centre of Healthcare and Medical Education, Bristol, United Kingdom
}

Email address:

carlolazzari2015@gmail.com (C. Lazzari)

${ }^{*}$ Corresponding author

To cite this article:

Carlo Lazzari, Abdul Nusair, Marco Rabottini. Psychiatry of Radicalization and Terrorism in the Lone Wolf, Children, and Women: An E-ethnographic Approach for Analysis. American Journal of Psychiatry and Neuroscience. Vol. 7, No. 3, 2019, pp. 57-68.

doi: 10.11648/j.ajpn.20190703.12

Received: August 10, 2019; Accepted: August 27, 2019; Published: September 10, 2019

\begin{abstract}
Radicalization is a global event affecting different countries and present in different historical contexts. Psychiatrists can help in the analysis of radicalization in individuals who operate autonomously from more radicalized groups. These lone actors or lone wolves are more difficult to spot as there is no unique identification because they operate as self-determined women or men. A focus of the current study is on the radicalization of children and women. The use of ethnographic research also using Internet sources has provided satisfactory results in the analysis of radicalization while reducing the risk and difficulties of approaching a sample population (terrorists, lone wolves, and radical groups) that, most of the time, is remote, dangerous and concealed to public scrutiny. Emphasis is also provided to the stages of development of radicalized thought and how radicalization can be understood in terms of cognitive and social development of the lone-wolf terrorist. The authors also explore how a radicalized leader can lever on the vulnerability of some individuals to radicalize them. Besides, the authors approach radicalized thought also as a logical fallacy and as a sign of dualistic thinking. Hence, a mix of cognitive, logical, and psychiatric triggers is analyzed in their potential to radicalize.
\end{abstract}

Keywords: Radicalization, Lone Wolf, Psychiatry, Ethnography, Internet

\section{Introduction}

Radicalization should not be counted as a new and abnormal process of socialization and historical development of a nation or a limited group of people. Instead, history has been punctuated by radicalization episodes. The transformation of any action into acts of psychological or physical terrorism depends on the socio-cultural evaluation at a specific historical moment. The actual decimation of children and women in conflict areas and different parts of the world might be perpetuated in the name of personal religious or patriotic agenda which appear justified to radicalized bands of rebels or to mercenary's armies who embrace their own or an unauthorized political agenda. Nevertheless, any act of inflicting harm on others with the pure desire and aim to have victims identified as opponents of one ideology should be scrutinized as representing, indeed, an act of radicalization.

The Lexico Dictionary Online defines radicalization as "the process of causing someone to adopt radical positions on political or social issues" [1]. Radicalization has also been defined as a behavior by which individuals embrace a political, social, or religious ideology that leads to terrorist acts [2]. Prevent (the British agency for the prevention of radicalization) defines radicalization as the practice leading people to endorse terrorism or radical ideologies leading to terrorism [3].

Lone wolves are radicalized individuals that usually operate independently from a radicalized group; in some instances, they were trained or influenced by such groups and then became independent from them by operating individually or as a dyad [4]. Social and individual psychiatry have tried to identify factors which might create vulnerability to being radicalized. Although several theories have been proposed, 
there is high sensitivity in the research instruments to the detriment of specificity in the conclusions.

Hence, a lone wolf has self-radicalized, has no contacts with other extremist groups, plans a terrorist attack with no inspiration from other persons or organizations, and has no support for planning and executing a violent act [5]. Furthermore, a lone wolf has no direct leader while terroristic strategies and means are invented and managed directly by the lone wolf without any external order or control [6].

The current article will investigate the phenomenon of radicalization under the standpoint of social sciences. Different perspectives include the logical fallacies of radicalized thought and the analysis of the impact that stereotypes have on inter-group conflicts. Then, the inquiry looks into the influence that charisma and leaders have in affecting vulnerable people in becoming radicalized and lone wolves. The analysis concludes with a perspective on the radicalization of children and women.

\section{Methods}

\subsection{Ethnography in Radicalization Studies}

The methodology adopted in the current study is mainly qualitative. Ethnographic research addresses people in specific circumstances, as involved in events with an explicit intention and significance, and is characterized by specific demographic features [7]. Ethnographic research has been used to approach Belgian and Dutch families of men and women who joined Syrian extremist groups [8]. The role of the observer and research conducting ethnographic research in terrorism studies often involves direct contact with extremist groups, lone wolves, or a radicalized entourage. Other times, as mostly occurring in the current study, the research data emerged from indirect sources, internet blogs, and events happening in the countries that were familiar to the authors of the present paper. Ethnography offers occasions for investigations to discover, recognize and validate multifaceted collective relations that may motivate and regulate daily existence, control settings that persist concealed, impenetrable, and mysterious to broader observers and culture [9].

Besides, the complexity of data, explanations, justifications, and ideas in people who are radicalized can make their investigation and accounts of their motives not valid for research purpose as their descriptions are too subjective and often biased. For this reason, observational ethnographic data and expert observation can increase the validity of ethnographic data and the analysis of radicalization. Indeed, ethnography is a research method based on observation as visual data can catch aspects and degrees of social exchanges in the original environment more than words or transcribed accounts [10]. Aim of ethnographic research is to understand via observations and interactions with the community under analysis what is true in the native culture aiming to an informative validity over time [11].

The Internet has become a global village. Via the web, people communicate, diffuse personal ideas and discoveries, create new connections, and find inspiration for their own life, leisure, and studies. The weight of the Internet in the diffusion of radicalization and terrorism is undeniable. Similarly, the web is a source of data, accounts, and opinions about radicalization and radicalized people and can be used as a source of ethnographic research.

It is reported that the Internet does not have the limit of bringing the research in direct physical contact with the population under investigation while, at the same time, it is a window on many nations hence facilitating a cross-cultural investigation [12]. The virtual proximity to ideologies of extremist groups is often the only available instrument to access terrorists' propaganda and plans. Furthermore, the presence on the web of dramatic images and photos posted by terrorist groups to affect public opinion is a valuable source of information for ethnographic research also because the anonymity of the virtual channel abolishes the constraint of interpersonal defensiveness.

Similarly, access to the phenomenological and psychological turmoil of people who are radicalized is not accessible by using standard interview techniques. This result is that radicalized individuals instead chose anonymity and, at the same time, the virtual world of the web to make others aware of the complexity of their bereavement and viewpoints.

\subsection{Web-ethnography}

Individual narratives can be captured on the Internet hence representing a valuable source of data to access the subjective world of people who live distant from the researcher [13]. 'Webethnography' or online ethnography is the research method applied to the analysis of online discourses and items [14]. Lone wolves and sympathizers of terrorist groups use the Internet in order to learn and diffuse their ideologies. In fact, the concern of legal implications or community dismissal brings radicalized individuals to disclose their interests on the web, while research reveals that participation in web subgroups can influence conduct in the real-life [15]. Furthermore, the theory of lone-wolf radicalization mostly relies on the influence of the Internet to explain in what way individuals moved from pacific to radical political and religious involvement [16].

In conclusion, the use of e-ethnography appears a promising development of ethnographic research. In fact, e-ethnography is a discreet methodological approach which allows widening of social analysis [17]. In the case of radicalization studies, Internet blogs, information, or pages might be the only data available to make a detailed and global analysis of terrorism around the world. Furthermore, terrorist groups using the Internet for propaganda, and proselytism can disclose on anonymous web pages more that it would occur in a face-to-face experimental approach to research. The current study takes the e-ethnographic approach for the analysis. 


\section{Results}

\subsection{Logical Fallacies in Radicalized Thought}

Under the perspective of social psychiatry, the process of radicalization requires a sort of accepted imbalance of power between two strong personalities. One of these personalities is dominant and sometimes grandiose and corresponds to the radicalizer person or group, and on the other side, the lone wolf who is the individual who is in the position of dependence and submissive condition compared to those who radicalize.

Radicalization assumes different aspects not always identifiable with those diffused by media that usually refer to events that hit public opinion and the web. More subtle forms of psychological radicalization instead might develop in more chronic ways, for instance, because of the action of a charismatic and authoritarian leader surmounting the resistances of opposing groups by recruiting executioners to thwart the resistance of the own opponents.

We might even think that each historical event that results in the decimation of victims has a radicalized act of few or many people who identify themselves as rulers, the 'enlightened,' or leaders. It can be a dictatorial leadership, actions of rebels, or the simple unpopular decisions of a harmed group which challenges the established politics. In a more limited social scenario, like in underprivileged areas of a city, gangs of juveniles radicalize local adolescents and peers to commit violence and drug dealing. Embedded in altered social interactions, radicalization bears some social, economic, power advantage to the detriment of vulnerable populations or groups. The power imbalance in the terrorism and radicalization partly respond to the game theory where the gain might not immediately benefit the actors playing, who might die in suicidal terrorist attacks. Instead, what is aimed is to move the public opinion towards or against a specific idea or position.

More narcissistically or more grandiosely, the lone wolf attributes to the own radical action the power to create a difference (idea, position, politics, and religion) in the desired goals although this is not (always the case). In fact, the logical fallacy which the radicalized mind fails to acknowledge is that the reaction and disdain of causing victims will oppose the public opinion to the own desired goals and the game will have a loose-loose gain, or no winner considering that in many occasions, the fatalities are many, including the lone wolf and the own victims.

In order to persevere in erroneous or criticized behavior (radicalized acts aiming to innocent victims) the lone wolf is assumed to make some logic fallacies of thinking that, if held for a long time and having no arguments against them or self-criticalness, might become overvalued ideas or delusional beliefs. The primary aim of a logical fallacy is to lift a terrorist from conflicts of conscience and to make him or her more determined to radicalized acts.

The most common logical fallacy is called ad hominem, where a person (in our case, the radicalized person) attacks an adversary directly as a substitute for addressing the opinions of the adversary [18]. The ad hominem disputes reported in the literature consist in three significant forms, (a) the insulting variant where the person using the fallacy attacks verbally the opponent with derogatory comments, (b) the indirect variant where the opponent is attacked by subsidiary process of generating qualms in their motives, and (c) and the incongruity variant in which the attacker points to flaws in the opponent arguments or facts [19]. An example of ad hominem fallacy is when the lone-wolf terrorist attacks a religious center claiming that this act represents a punishment of followers of that religion and what they believe and represent.

One characteristic of logical fallacies is the presence of false reasoning which is 'deductively' false if the reasoning is deductive or inductively false if the reasoning is 'inductive'; furthermore, the psychological element is that the reasoning behind a fallacy appears to be persuasive [20].

Another logical fallacy is the false dilemma where a person assumes that two arguments cannot be correct at the same time, hence concluding the inaccuracy of one and the veracity of the other [21]. In this case, the terrorist assumes that co-existence between two different worldviews is incompatible, that people who believe in something that is not acceptable (to the lone wolf) are to be condemned as the argument of being acceptable and being an opponent cannot be correct at the same time.

Cognitive categorization or generalization is like a false dilemma. In this case, the person who uses cognitive generalization erroneously assumes that the characteristics of one group member might be universal and applicable to other groups' members [22]. Hence, a terrorist might feel entitled to categorize all members of a target group with negative qualities just because one member of that group was deemed as 'unfair' or 'cruel' towards the lone wolf or a member of the group with whom the lone wolf identifies him or herself.

The rivalry between different groups is usual in political scenarios. However, radicalization and terrorist acts performed by lone wolves occur based on generalizations and stereotypes that the lone wolf holds about rival persons, groups, and nations. Preconceptions mixed to stereotypy can lead a person or a group to overrate the amount of disparity between the own ideas and those of their opponents, to judge the groups of the opponents very different from the own group, to feel anger towards out-group, and to hold biases towards the ideas of the own groups [23].

Stereotypes have both a cognitive goal, by filling the gaps of missed information (for instance, about others and opponents) and by boosting self-esteem by attributing negative and derogatory qualities to others and rivals [24]. When a group or nation perceives weaknesses into the own citizens and members, the creation of a hypothetical adversary or rival can help increase internal cohesion while reducing the likelihood of blaming self for the internal problems. Someone else is to blame!

\subsection{Radicalization, Terrorist Leadership, and Followership}

It has been emphasized that lone-wolf radicalization and terrorism is the action of a single person who might or might 
not be influenced by a leader, group, ideology, or propaganda. However, in the real world, each one is somewhat influenced by others and by persons who are influential and have charisma. Merriam-Webster dictionary online defines 'Charisma as a special magnetic charm or appeal' [25]. Hence, a radicalized act can be simply the action of a ruler surmounting the resistances of an organized group of citizens to impose inhuman restrictions and regulations in a dictatorial country. The force of autocratic authority and the limitation of liberty imposed on the population can have an appealing effect on gullible persons who perceive the magnetic effect of a ruler, and the opportunity to achieve status by becoming loyal affiliates. These dynamics probably feed right-wing extremism and terrorism.

Due to increased homophobic movements, facing social and ethnic disparities, moved by resentment and anger, challenged in recognition of their rights as citizens, more and more people in Europe and USA start to see radical and violent solutions as the only way out of inadequacies of local governments and social agencies. Hence, radical right-wing movements are becoming more and more popular while attracting young people who see affiliation to extremist groups and radical actions to punish governments, countries, legislations and so on [26].

Radicalization is linked to some ideology. Also, if the lone wolf operates independently from more organized groups or countries, he or she uses a personal idea of justice and revenge. Collins Dictionary Online defines 'An ideology as a set of beliefs, especially the political beliefs on which people, parties, or countries base their actions' [27]. Followers are linked to the ideology of charismatic leaders and would act in ways that would be considered as individually unreasonable because terrorists are inspired by their leaders' charisma and would act on leaders' behalf instead of behaving by seeking individual profits [28]. The analysis of lone-wolf radicalization suggests that a charismatic leader does not need to be physically present and have face-to-face contacts with the active terrorist. Instead, a leader's ideology can persist via symbols, books, pamphlets, web sites, or the description by other followers.

The fight against terrorism by addressing a leader and his or her ideology can bring to the desertion of followership when no-one can fill the gap; instead, the recent lone-wolf terrorists indicates that there is one single person holder of radical ideology which might diffuse by phenomena of emulation [29]. Psychiatrists might be worried about aspects of ideological prejudice deriving in the context of interpersonal relationships. There might be someone with charisma, who has been able to convince an emotionally weak person in search of identity, revenge or power, that some idea was right, and that the truth can emerge if there are victims in those who do not believe in this truth. The scope is similar, as there are always victims. The terrorist leader's or lone wolf's aims also are identical as they try to coerce an idea, action, or truth to the victims by any means. What can change are the means, which in some case is political propaganda, in others, wars or a car running on people in public places of crowded towns. The dilution of radicalization into so many aspects reduces its impact, but only apparently, as it should be considered as a social and historical event much more diffused and worrying and less episodic and unexpected that is believed.

A sort of psychological vulnerability should be suspected in lone wolves who are easily susceptible to fervent ideas, images, and propaganda. For instance, there is some theory that autistic people are more vulnerable to radicalization [30]. It is reported that Autism Spectrum Disorder (ASD) shows a high incidence in the lone wolf, and although people with ASD are not antisocial, people with autism have altered productive relationships in the social context [31].

Authors report a case of Asperger Syndrome who became radicalized to extreme right-wing ideology suggesting that some traits like lack of empathy, interpersonal obstacles, and schizoid personality can put persons with Asperger at risk of radicalization [32]. The other risk fact is that people with autism are more easily targeted for recruitment in terrorist attacks due to their desire of greater social connection, their inadequacies to analytically comprehend attitude and philosophies of a radicalized group, and inclination to concentrate only on façade features [33]. A mild depressive illness is also associated with the risk of radicalization, together with the support of passionate remonstrations and radicalism [34].

In conclusion, a mix of charismatic leadership and individual personality in followers can generate triggers for radicalized thoughts. Although several factors have reported as linked to radicalization, no single feature is a sufficient condition for explaining the phenomenon. In fact, a multifactorial process should be considered (Table 1). Due to the complexity of the radicalization process and the recruitment of active terrorists, there might be a chain of persons that go from the charismatic leader to the suicidal terrorist. In the case of lone-wolf radicalization, the chain might be missing, and the actions of planning, ideological justification, bereavement, and attack all reside in one person.

Table 1. Stages and persons in the radicalization process.

\begin{tabular}{ll}
\hline Participants to the chain of terror & Their actions \\
\hline Planner or organizer: & 'The mind' of the organization or charismatic leader. The lone wolf can be the only planner \\
The intermediary or facilitator: & The person, group, or organization that advocates the terrorist attack. \\
The responsible terrorist: & The individual or group directly responsible for the terrorist attack. \\
\hline
\end{tabular}

\subsection{Social Psychiatry of Radicalization}

The most familiar forms of mild to severe radicalization in
European countries are linked to partisanism of extremists' political parties. History has been punctuated by terrorist attacks promoted by extreme left or right wings of the local political parties. Sadly, these actions have been soothed by 
partisanism, and the definition of terrorism has not emerged so quickly. In a country where there are diverging political parties in open conflict and civil war, there are actions of radicalization and terrorism almost daily addressed to neutral citizens as opposing political wings aim to recruit allies to their group. The propaganda of a 'just cause' has thus led to a historical weakening of inter-ethnical and social acceptance while emphasizing unproven diversities and troubles in inter-ethnical bonds. Such a condition has promoted more radicalized and partisan thinking when people address and emphasize alleged differences within ethnic groups in their country or conflict areas in the world. In some extent, the 'invention' of an enemy or external disturbance has always been an amalgamation force that reduced group disintegration. Radicalization is feeding wars that continuously appear in the social scene when the economy and politics of each country is finding difficulties in maintaining internal order. The seed of riot and radicalization exists in the very and tight ethnic quarters of each cosmopolite town. Here, more than everywhere else, the feelings of us-they are easily diffused and diffusible.

People speak the language of the original ethnic group but might have some resilience to interact with the local culture, beliefs, and habits fully. The history of terrorism in European countries is linked to political and partisan movements of the extremist fringes of the local parties. This phenomenon is most prevalent in Europe whereas, in other countries, like in some countries of South America or Central Africa, radicalization is linked to local dictatorship while dictators are the only radicalizers and rulers present in the geographical scenario. In this case, refusing to be indoctrinated and radicalized can cost the lives of those who are not aligned with the prevailing dictatorship.

The scenarios of political radicalization of extremist parties can illustrate some modalities that persist throughout modern-day terrorism. Whenever there is internal and political instability in a country, there are radicalizers, rules, dictators, or politicians who feel that they can thrive among people and societal confusion. In the name of strong ideologies of national identity, self-made leaders attempt to instigate conflicts. Extremist and patriotic messages have an easy catch on gullible persons, fed by chronic feelings of dissatisfaction with local or foreign countries, and nourished by anger; hence, biased radicalized persons can see violence as justifiable in their circumstances. Additionally, subjects with specific psychiatric disorders such as antisocial behavior, conduct disorder, attention deficit, and hyperactive disorder (ADHD) are more inclined to violent behaviors and being enticed by extremist ideologies [35].

The Latin 'Divide et Imperat' meaning 'Split and Rule' is a form of radicalization. The radicalizer, that is, the person who influences others to radicalize them has several ambitions such as not to act in the first person, not to be discovered, not be blamed and persecuted for a terrorist act. Hence, the terrorist attack can happen as the last ring of a sequence of actions, mostly ideological indoctrinations that make it challenging to identify the main responsible of the terrorist plan. The network from the initial ideology and charismatic leader to the final terrorist is so ingrained and hidden that the 'minds' of a terrorist attack easily escape from a direct charge unless they publicly claim that the radical violence was under their patronage and order.

Media can have a significant impact in indoctrination while allowing physical separation between the charismatic leader and the radicalized lone wolf. A terrorist leader has the skill to reinforce the distinctiveness and self-esteem of those who feel repressed while activating affection for the in-group, hate for the out-group, and using media to achieve trustworthiness [36]. Images on mass media of supposed victims of the in-group, who have suffered torture and mortification, can induce a sense of companionship and can easily affect the emotions of those high in need of reaching conclusive solutions [36].

As shown in Table 1 the process of radicalization undergoes different stages which include the mind or leader of the ideology, those who diffuse the doctrine of the guru, and those who accomplish the terrorist attack such as the lone wolf. As Table 1 suggests, some possible intermediaries or promoters convey the radical ideas of the charismatic leader or group to the lone wolf. Nonetheless, the geographical proximity of these actors can be missing as media, Internet, and books of propaganda can suffice the transmission of radical ideas from a charismatic leader to the lone wolf.

Hence a short or long-chain of grief and feelings of revenge goes from the news of people who are innocent victims of conflicts to the lone wolf who believes that he or she is called to terminate injustices in the world. On one side of the chain, those who are planning revenge, and at the opposite side, the lone wolf. This chain makes it difficult to understand when and where the lone wolf will attack because it is not (always) possible to anticipate the crisis moment that brings a vulnerable and naïve mind to take the life of innocent persons.

Often, the radicalized lone wolf might independently take direct responsibility for the terrorist act, although a seed of radicalization either exists in the own history or reflects learning and personal interpretations acquired directly or indirectly via media or interpersonal face-to-face contacts.

In more planned forms of political and social radicalization, there is a neat divide between who is planning the terrorist attack and the person who performs its. However, in the case of the lone wolf, the whole process from planning to execution can reside in the same person, and no real 'planner' or intelligence is found. In this case, the terroristic action is much the result of anger and unplanned behavior of a person with a dissocial personality disorder who is chronically in the fight against the total institutions, the government, and the authorities.

Other times, several extremist agencies with impermeable boundaries and controlled communication and information sharing deal with each of these stages. It then happens that who is planning, the 'mind of the organization,' will recruit via covert or overt propaganda gullible people, antisocial persons who are known to be corruptible, needy or problematic and who can be recruited to offer their help in unlawful plans.

Radicalization involves both men and women. In American 
study, it emerged that many women were initiated to radicalization by at least one other person in about $65 \%$ of the cases, in $90 \%$ of the cases family or friends both endorsed and were engaged, while in $60-70 \%$ of the cases radicalization began or was reinforced via the Internet [37]. It is also reported that far-right extremists are targeting children via Internet enlistment communications [38]. Children can be exposed to extremist ideology via online social networks or strangers while, in extreme cases, they can be forced to leave their family to affiliate with extremist groups, possibly abroad [39].

\subsection{The Radicalization Pathway}

There are several social scenarios where radicalization is possible also outside a terrorist setting. In more familiar forms, even in a smaller social scale, radicalizer is the authoritarian leader in conflict areas or mob boss that tries to abduct or radicalize local juveniles to ranks of punishment squads. In milder forms, political parties next to conflicting elections engage in some types of accepted radicalization and indoctrination with aims to gain consensus in the majority. Hence, radicalization to ideologies is not a novel process in the social scenario and has to do with an imbalance of power, coercion, anger, violence, revenge, and social instability.

Those who tend to maneuver feelings and consensus do so in a radical way as violence can have for the radical terrorist or sympathizer some payoff such as achieved status by fear, higher recognition, social affiliation and integration, personal satisfaction, higher visibility and social recognition in the in-group in the case of martyrdom following a suicidal attack.

In more domestic forms, radicalization can occur as the lone wolf is in a condition of extreme need that acquaintance to a radical act and the risk involved appear tolerable more than the personal situation that the lone wolf is trying to overcome, and which is creating the grievance and anger towards potential victims, like in the Scenario \# 1 .

No matter where the scale needle hangs in historical events, the gradual process of embracing an idea, no matter how violent, which leads to the aim to enforce it to others using force, restriction, terror, and death, characterizes the nature of radicalized movements.

Scenario \# 1.1. Fictional narrative from merging different dramatized stories with historical validity

Social drift: the year 1960. A tremendous economic depression hit the local geographical area [details omitted]. Many men and women were made redundant from their job, and it was not was possible to find a new one.

"I started to associate with extremist groups and the local mob after I have lost my job. I was working in a garage, but my boss was always against me and my way of working. One day, I was made redundant and sent home with no explanation. I felt depressed, and I started to drink more than usual. I could not sleep, and I felt mounting anger. I was becoming aware of social injustice and the fact the immigrants to my country had better treatment and salary than mine. I spoke about this with some friends at the local pub. One day I was approached by someone who did not introduce himself but was known as an important boss of the local mob. Not many words. I remember he just told me, "I understand how you feel." He gave me an envelope with about 200 Euros. After one week, the same gentleman came accompanied by two other men. Again, no words. One of them told me that they felt that I was the 'real man they needed.' I felt important again, and I had a value in society. This time they gave me a book with some money inside and a phone number a could contact when needing help. I felt I could not go back. I did not want to. I had too much to lose now. The first 'job' was told me by an anonymous phone call by someone who did not identify himself. I knew it came from those men, but I never had any direct contact with them anymore neither I tried one. The 'job' was to distribute fliers to young people in a specific area of the town or country, to move their souls, to generate chaos, to promote strikes, and similar 'diversions.' I always had indirect orders, and I was paid via envelopes with more and more cash while cocaine appeared for the first time. Never a direct contact or name I could identify. Orders arrived by phone with a disguised voice. Books were given to me about war conflicts in the world, or odd spiritual beliefs, or stories of people who were unemployed like me in the past. I felt that they were trying to give me a reason for going ahead and being an ally. One day, I had to recruit younger people like me to feed a strike to create 'chaos.' Nothing I was interested. However, the 'organization' felt that enough chaos from the strike could alert the attention of the media. I believe I was radicalized in the sense that my lifestyle changed drastically. Sport cars, money, cocaine, a new flat but I also became ruder, colder, arrogant, and excited about my new identity and power. I was no longer thinking and feeling like when I was unemployed, but I could not say that what I became was better."

The instruments that are used to diffuse ideologies are multiple, either directly going from the ideologist to proselytes via media or indirectly using books, leaflets, flyers, meetings, etc. The indirect indoctrination via readings allows the ideologists to impact on minds without being much exposed. This event has also been reported by radicalized people who confess that 'someone had approached them and gave them some revolutionary books to read.' Cognitive dissonance, resistance, and doubts can be overcome by radicalizers if they praise a person, the radicalized, for the reading. Also, vulnerable people might have no critical understanding of written propaganda hence accepting them forehand as a matter of truth.

The radicalized usually and necessarily remains in Perry dualistic stage. This event happens because the dualistic stage also allows a paranoid projection and the cognitive creation of the identikit of potential enemies: the victims. Instead, more advanced stages of cognitive development would create a cognitive dissonance as relativism is implied, thus the idea that not all truths are absolute, which, per se, is in conflict with the absolutism triggering a terrorist attack. Rapaport suggests that in Perry's stage of cognitive development corresponding to 'Dualism' each form of knowledge that is received by the individual is perceived having a dichotomy of right or wrong with no alternatives or links between absolute truths (Table 2.) $[40,41]$. 
Table 2. Perry stages of cognitive development in normal and radicalized individual (see Rapaport [40, 41]).

\begin{tabular}{|c|c|c|}
\hline Perry's stage & Perry's stages of normal development & Perry's stages in radicalizing \\
\hline Dualism & The knowledge received is not questioned & $\begin{array}{l}\text { During the early stages of radicalization, individuals accept ideas, norms, and values } \\
\text { from radicalized web sites as a matter of truth. }\end{array}$ \\
\hline Multiplicity & $\begin{array}{l}\text { A person recognizes that there is more } \\
\text { than one solution to a problem }\end{array}$ & $\begin{array}{l}\text { Multiplicity might be frozen in radicalizing families as the radicalized individual is } \\
\text { educated that for a problem, there is only one solution, and other explanations might not } \\
\text { be acceptable or viable in his / her sociocultural entourage. }\end{array}$ \\
\hline Relativism & Knowledge is seen as contextual & $\begin{array}{l}\text { The radicalized people might lack proper ethical or social development to consider that } \\
\text { their understanding is not right out of their family or social milieu. If the milieu is } \\
\text { radicalizing, then, the individual is radicalized to the prevailing ideologies. }\end{array}$ \\
\hline $\begin{array}{l}\text { Commitment } \\
\text { with relativism }\end{array}$ & $\begin{array}{l}\text { Integration of the own knowledge with the } \\
\text { data acquired from other sources }\end{array}$ & $\begin{array}{l}\text { In the radicalized individual, the personal knowledge is not questionable, and there is a } \\
\text { cognitive rigidity to incorporate only ideas and information that does not conflict with } \\
\text { the radicalized core values of self and their cultural milieu. }\end{array}$ \\
\hline
\end{tabular}

Dualistic thinking belongs to people who had problematic upbringing. In radicalizing families, children are dualistically taught that only some people are always (usually from their own ethnic or religious group) respectable while others are evil. Radicalized children might hence develop out of dualistic upbringing and thinking. In some instance, children's acceptance of family radicalization is instinctively acknowledged if the dualistic ideology does not endanger or contradict the pathological role models (in the family) to whom the child is exposed. Besides, a radicalized child might remain in the dualistic stage, also during adolescence and adulthood [42].

The dualistic stage allows a paranoid projection and the cognitive distortion of the identity of potential victims located outside the family's ethnic group. Hence, when a radicalized child and adolescent start to endorse family's negative qualifications of distinct others, these last can become easy victims of retaliation and terrorist attacks presently by the child or adolescent (diagnosed with challenging behaviors), or when the child has grown up into an adult (diagnosed with a dissocial personality disorder). Mental-health professionals working in the community can identify the early signs of dualistic thinking in radicalized children. These last require more attention to avoid pathological upbringing into terrorist adults. The aim is to implement community support of children and adolescents who show the seeds of radicalization and to improve their cognitive skills and dualism by helping them accepting alternative thinking without challenging children's role models

A cognitive split and dis-empathy occur in radicalized persons towards their potential victims. Lack of empathy for the victims of a terrorist attack is generated by the processes of cognitive separation and paranoid generalization. During the Stage of Cognitive Separation (SCS), the radicalized person does not think of victims as individuals but as a group representing what that the terrorist hates. A physical, emotional, and psychological separation between the radicalized terrorist and his or her victims reduce empathy and moral conflicts towards their actions. Throughout SCS, the radicalized person appears more aloof, inaccessible, and persuaded about his or her beliefs. During the following stage of Paranoid Projection, the targeted victims are progressively defined by their negative attributes via cognitive distortions, including absolutism and projection. The stage of paranoid projection is the process of victimization where distorted cognitive beliefs about potential victims are reinforced to reduce cognitive dissonance between personal moral judgment and planned terrorist actions [43].

\subsection{The Radicalization of Children}

Dualism and the creation of stereotypes, hence the radicalization of children can occur in sociocultural environments when there are conflicts within ethnic and religious groups. Families are unaware that their discourse about 'others,' 'truths,' and 'injustices' are automatically absorbed by their children and from there to the next generations. In some sense, a process of ideological radicalization can be intergenerational and becomes a spontaneous process for the family and children who familiarize with a narrative that is already a radicalized way of interpreting the world, the others, and the society. Children are usually discouraged from challenging these prevailing ideas and ideologies while they view them as 'logical' because the whole social and family network maintains them.

As reported in Web blog \# 1.1., national organizations are aware that children belonging to different ethnic groups are victims of radicalization and indoctrination in their own families. This phenomenon risks to diffuse radicalization rapidly as there may be many children in the same family while radicalizing ethnic groups accept ideologies of separation and violence towards the out-groups.

Web blog \# 1.1.

"Radicalized children pose security 'risk' in Germany."

Germany's Federal Office for the Protection of the Constitution has advised that several hundred children are at risk of radicalization while creating a threat to national safety. It is reported that there is an increased number of children and adolescents growing in families that indoctrinate radical ideas which accept aggression towards others and depreciate those who do not suit into the own ethnic and religious group [44].

Radicalization can appear as early as in childhood, as also reported by major observatories and studies [45]. The mind of a child is gullible and accepts as a matter of truth, whatever are the messages and ideology that family and important others 
inculcate in them. The National Society for the Prevention of Cruelty to Children offers warning signs that the child might be a victim of radicalization [46]:

a) A Detachment from family and contacts.

b) Using jargon or speech that seems to be written in advance.

c) A reluctance or failure to debate their opinions.

d) An unexpected and discourteous manner towards others.

e) The mounting intensity of irritation.

f) A greater caution in talking about Internet practice.

Local governments are making substantial efforts to reduce the radicalization of children who for their nature are an easy target of terrorist groups always looking for new followers. However, terrorist groups or a radicalized milieu are challenging to eradicate while extended groups of children might be methodically radicalized at the same time. Some areas of the world are more vulnerable to have extremist groups which can reach out families and children with little resistance from the local community or government (Web blog \#2.1.).

In other cases, the actions of radicalization of children are less evident although happening in our schools and towns. The way that extremist groups use to reach targeted children can be direct or via telematics (mostly Internet) channels [48].

Web blog \#2.1.

"Boko Haram: Nigerian Army hands over 183 radicalized children to UN."

"The Nigerian Army on Monday formally handed over 183 children linked with armed group Boko Haram in the Northeast to the United Nations Children and Education Fund (UNICEF) for rehabilitation" [47].

The journal International Business Time suggests that children get radicalizing messages online (Web blog \# 3.1.) [49]. The same source suggests five steps for parents to protect their children from radicalization [49]:

a) Becoming aware of children's new friends while making sure that parents know who the new friends are.

b) Observing any radicalized behavior and becoming aware that children are at more risk of being influenced if their friends are radicalized.

c) Noticing any change in habits, especially if children spend more time on the Internet while parents should know which websites are visited by their children.

d) Detecting any change in fashion and eating customs which might indicate affiliation to same habits in radicalized groups.

e) Opening to discuss topics of radicalization with their children while observing any reaction to these topics.

Children and adolescents represent a vulnerable yet preferential target for radicalizers. The process of deradicalization makes sense if it is applied during crucial moments of a child's cognitive and moral development. After a child has been radicalized for a long time, the change of the cognitive schema becomes more problematic (Figure 1.).

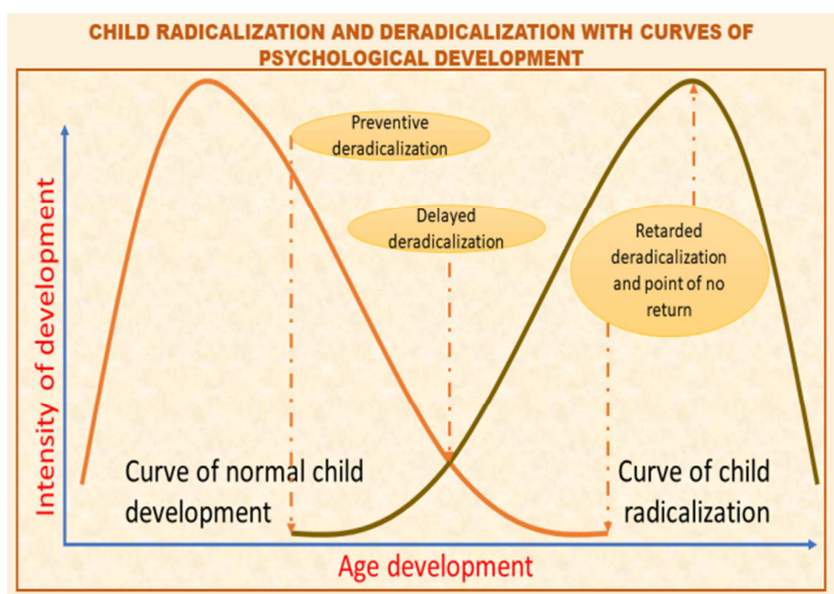

Figure 1. The curve of child average neuropsychiatric development declines with the increase of child degree of radicalization. At the beginning of the process of radicalization, it is still possible to act on a child's psychology and achieve a successful de-radicalization. However, as the process of radicalization progressed, a child becomes more rigid in his thinking by starting to form a strong alliance with the radicalizing source, hence resistant to change the radicalized ideas acquired.

Following is the summary of early signs of radicalization in the child although none of the signs are indicative of radicalization but the consequences of it:

a) Retarded neuropsychological development; not a condition implying radicalization but a consequence.

b) Unexplainable mood changes inclusive of depression, behavioral changes, challenging behavior, stubbornness, rigid thinking, anger, social isolation from peer groups.

c) In projective tests, educators can find some hint of the events the child is exposed to, like family indoctrination and radicalization, familiar and detailed description of weapons and bombs. Furthermore, during childhood, the child engages in solitary games. Lack of playful activities and presence of aggressiveness and role-playing domineering characters.

d) Teachers and school psychologists record a decline in school achievement, rigidity in thinking, isolation in and from the peer group, reduction in playful activities, constant sadness and preoccupation with the own thoughts that are not shared or shareable. When alone, the child spends a large amount of surfing on the Internet or mobile phone.

e) In his plays, the child repeats some radicalized action like shooting, fighting, creating bombs, killing, bullying, and often targeting school friends and other peers.

Now, there is a great concern about the risk of radicalization of children in young age while major organizations are alerting families and schools about this risk. As highlighted by many sources and in many studies, the thinking of a radicalized child is peculiar, and a form of rigid stereotypy is the first to appear. The child might also be living in a radicalized family; therefore, signs of psychological and cognitive conflicts might lack. Nonetheless, radicalized children might appear to have hostile attitudes towards their school mates, especially if from other ethnic groups.

Radicalized children might isolate themselves from 
companions from other ethnical or social groups or faith while holding rigid stereotypes when describing other companions that are not from their own socio-cultural background. Behaviorally, radicalized children might have little involvement in social plays and behave like 'little adults.' In the case the child is newly radicalized, he might be troubled by internal conflicts between being like others and moving towards the 'new (radicalized) ideas.' How to distinguish a naturally or newly radicalized child is not straightforward. More profoundly, radicalized children form a sort of emotional alliance towards the source of their radicalization: family, a social group of origin, Internet, radicalized adults, and so on.

Form a medical and psychiatric point of view, radicalized children have problems in thriving, difficulties in sleeping or appetite, perhaps some show mild developmental and cognitive delay while missing educational and school targets and appearing not concerned about the feedback from teachers or educators. School psychologists might find a problematic interaction with these children, apart from stereotyped thinking and talk; they appear aloof or defensive in disclosing anything about themselves. In more projective tests like drawings, young children might show worrying patterns in figures, colors, or merely a lack of creativity and patterns that are expected in this age.

Schools and nurseries in the UK have been alerted to notice signs of radicalization in children (Web blog \#3.1).

Web blog \# 3.1 .

"Nursery staff urged to look for signs of radicalization."

"Nursery workers are being urged to be on the lookout for signs of radicalization in parents amid concern about families leaving Britain to travel to Syria. The National Day Nurseries Association (NDNA) said nurseries played a vital role in teaching tolerance of different faiths and backgrounds to children in their most formative years" [50].

The Guardian described the story of a child drawing his father making a cooker bomb. Hence, children draw what happens around them or represent family events in their drawings or narratives (Web blog \# 4.1.). Nonetheless, no matter how a child becomes radicalized, there is an interruption of his or her basic needs such as the freedom to think or play, attachment, play, and other basic milestones of development. Hence, the radicalized child soon displays depression, anger, frustration, insomnia, fear, flashbacks, challenging or fearful behavior, and physical or emotional isolation.

Web blog \# 4.1.

"Nursery 'raised fears of radicalisation over boy's cucumber drawing."

"Staff at a nursery school threatened to refer a four-year-old boy to a de-radicalisation programme after he drew pictures which they thought showed his father making a "cooker bomb," according to the child's mother" [51].

In conclusion, psychiatrists, mental health professionals, and teachers are in a privileged and responsible position to detect early signs of radicalization in children and adolescents. Furthermore, a young mind in its development and a dualistic cognitive stage represents the favorite target of radicalizers and terrorist groups. Hence, due to high vulnerability and bias in children thought every effort should be made in order to avoid that irreversible radicalization occurs in children development with the risk of permanent impairment of children's emotional, cognitive and moral development.

\subsection{The Radicalization of Women}

Radicalization can occur as a one-step and global process. The allure to have a different life or to get into some unique experience appears to be one element in the history of Shamina Begun a young and successful British girl, described as a 'normal girl' who decides to travel to Syria to become the bride of an active terrorist (Web blog \# 5.1.) [52].

As in the account of Begun, there is no preventive process of indoctrination; the radicalization derives from an intrinsic personality of some young women to have a drastic and catastrophic break from routine and to join extremist groups. The element of psychiatric vulnerability should be considered in the personality range. Rebellion is not a psychiatric diagnosis, nonetheless, anger plus narcissistic personality could be.

Web blog \# 5.1.

"Isil bride Shamima Begum 'considering challenging' Home Office decision to revoke her British citizenship."

"The 19-year-old, who had expressed the desire to return to the UK with her newborn son, will now be banned from entering the country" [52].

The desire of innovation and uniqueness is intrinsic to the history of Begum itself; longing for the total separation from routine and acknowledged reality, from wealth and wellness, and forming of a new link to unknown and opposite ideals, countries, and standards. As the article Telegraph underlines, there is no cognitive impairment [53]. Therefore, Begun's decision is taken in a full conscience (Web blog \# 6.1.).

Web blog \# 6.1.

"How Shamima Begum and two other schoolgirls from Bethnal Green became Isil brides."

"At 15, Shamima's young mind was filled with much more than the affairs of the most famous family in Hollywood. Four months before she was due to sit her GCSEs, Shamima - the daughter of Bangladeshi immigrants, by all accounts a "sensible girl" and a "talented and dynamic" student at the high-flying Bethnal Green Academy - was secretly planning to leave her family and the only home she had ever known in London's East End, and travel to Syria to become a jihadi bride" [53].

The emotional drive of novelty which much overrides stability is fuelled by a phantasy about a country and a marriage with an extremist terrorist raising the suspect that pathological personality traits could be present in this case. Hence, the cognitive part, the capacity of making rational decisions is missing due to the emotional naiveté of a 15-year-old girl together with an autonomous decision which has not received peers and parental approval; the example suggests the hypothesis of a narcissistic and antisocial personality disorder. 
Thinking remains dualistic and egocentric as the girl has taken as a guideline the own emotions and the push of companion girls who also wanted to become brides of extremist groups. From here, one conclusion, radicalization can be favored by peer pressure and become a form of 'fashion' and 'attractive experiment' as demonstrated in this case. The cognitive interpretation can be interpreted as reverting from relativism to dualism. In order to master her studies, Begun demonstrates full cognitive skills to grasp relativistic thinking.

However, due to a cognitive crisis, she goes back to dualistic thinking and rejects her own country, her family, her peers to become the bride of a terrorist. The hypothesis is that cognitive and moral development 'somewhat regress' if there are psychiatric conditions and emotional turmoil that push the person to former and more immature emotional and cognitive skills (Figure 2).

One research suggests that women who become radicalized satisfy the conditions of a 'Dark Tetrad' inclusive of Machiavellianism, narcissism, sadism, and psychopathy [54].

Experts in the culture of Muslim women report how important was for the radicalization of women their perception of rejection from their community linked to feeling marginalized, disqualified, and victimized because wearing traditional Muslim clothes [55].

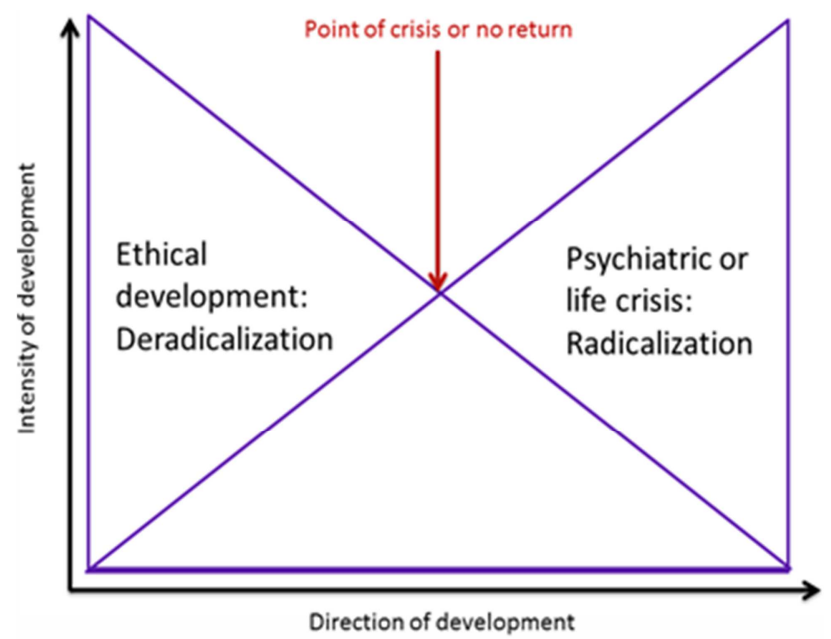

Figure 2. A psychiatric crisis, like any process of life crisis, can reduce and challenge the moral development. There is a point of no return as each psychiatric crisis is accompanied by a reduction of ethical development as the person becomes more self-focused. However, as the psychiatric crisis deteriorates, also ethical development is reduced, and the person utilizes lower-level ethical skills and radicalization is facilitated. Life crises can reduce and challenge the moral development and pull the person to former emotional and cognitive stages.

In conclusion, radicalized women are equally important in the scenario of an international terrorist. Either as active terrorists or brides of terrorists, radicalized women are vulnerable to the allure of drastic changes in their lifestyle if vulnerable personalities are present. The research investigated does not confirm the existence of major psychiatric disorder while a mix of narcissistic personality or catastrophic personality changes can be suspected if women victims of radicalization do not live in a radicalized environment. Also, in this case, the propaganda of extremist groups can reach vulnerable women via the Internet bypassing any family and societal filter. Online messages from radicalized groups directly target the mind of vulnerable women who might seek on the web inspiration and solutions for a 'different life.'

\section{Discussion}

The current study has analyzed the phenomenon of radicalization and terrorism in the lone wolf with a particular focus on the radicalization of children and women. As explored in the current article, e-ethnography can help researchers access societal aspects, motives, behaviors, and ideologies that propagate radicalization. As also observed in the online accounts and in the cases explored, no single factor could be addressed as fully responsible in triggering a terrorist act. The complexity of ethnic and geographical variables which make radicalization a global concern was approached by unobtrusive ethnographic methods with the analysis and discussion of web blogs and stories linked to radicalization. The authors of the current article utilized an e-ethnographic approach for the analysis of a global phenomenon and to create inductive theories on radicalization and terrorism. Such a method has given satisfactory results while reducing the risks and difficulties of approaching a sample population of terrorists, lone-wolves, and radical groups that, most of the time, is remote, dangerous and concealed to public scrutiny.

\section{Conclusions}

The current study has highlighted a novel approach for the study of radicalization and terrorism. The authors have approached two major sensitive topics, the radicalization of children and women. The aim was to propose a novel way of studying the phenomenon and provide social scientists with valid instruments to understand and prevent radicalization. The use of ethnographic research has provided an in-depth understanding of radicalized persons and their cultural context.

\section{Recommendations}

The authors of the current research recommend the use of ethnographic research methods and the analysis of online narratives as an alternative method to study radicalization. Although other direct methods of approaching radicalized persons have been used in other researches, it is not always possible to explore the intricate behaviours and motives of radicalized cultures who use the internet to diffuse their propaganda and to justify their actions.

\section{Author Contribution}

All the authors contributed to the design and implementation of the research, to the analysis of the results, and to the writing of the manuscript. 


\section{Conflict of Interest}

The scenario described as a case study was created according to merging different episodes, people, life stories, researches, and events that either occurred in the authors' clinical practice or were public events. By no means, there is a specific referral to real happenings unless it is otherwise specified like in the 'web blogs' sections. This last occurrence is usually linked to facts reported by the Internet. Therefore, the authors have no conflict of interest in the disclosure of the narratives reported and in the publication of the current study.

\section{Acknowledgements}

The authors of the current research acknowledge their collaborators and sponsors for providing insights, suggestions, and narratives that helped in the completion of the article.

\section{References}

[1] Lexico Dictionary Online (2019). Radicalization | Definition of radicalization in English by Lexico Dictionaries. [online] Lexico Dictionaries | English. Available at: https://www.lexico.com/en/definition/radicalization [Accessed 3 Jul. 2019].

[2] Misiak B, Samochowiec J, Bhui K, Schouler-Ocak M, Demunter H, Kuey L et al. A systematic review on the relationship between mental health, radicalization and mass violence. European Psychiatry 2019; 56: 51-59.

[3] Secretary of State for the Home Department. Prevent Strategy [Internet]. Norwich: TSO (The Stationery Office); 2019 [cited 30 May 2019]. Available from: https://assets.publishing.service.gov.uk/government/uploads/s ystem/uploads/attachment_data/file/97976/prevent-strategy-re view.pdf

[4] Gill P, Horgan J, Deckert P. Bombing Alone: Tracing the Motivations and Antecedent Behaviors of Lone-Actor Terrorists. Journal of Forensic Sciences. 2013; 59 (2): 425-435.

[5] Borum R, Fein R, Vossekuil B. A dimensional approach to analyzing lone offender terrorism. Aggression and Violent Behavior 2012; 17 (5): 389-396.

[6] Hamm M, Spaaj R. Lone Wolf Terrorism in America: Using Knowledge of Radicalization Pathways to Forge Prevention Strategies. Indiana State University; 2015. Available from: https://www.ncjrs.gov/pdffiles1/nij/grants/248691.pdf [Accessed 6th June 2019].

[7] Angrosino M, Flick U. Doing ethnographic and observational research. Los Angeles, Calif.: SAGE; 2009.

[8] van San M. Belgian and Dutch Young Men and Women Who Joined ISIS: Ethnographic Research among the Families They Left Behind. Studies in Conflict \& Terrorism. 2016; 41 (1): 39-58.

[9] Parkin S. Observant participation with people who inject drugs in street-based settings: reflections on a method used during applied ethnographic research. Addiction Research \& Theory. 2016; 25 (1): 39-47.

[10] Rhodes T, Fitzgerald J. Visual data in addictions research: Seeing comes before words? Addiction Research \& Theory.
2006; 14 (4): 349-363.

[11] Crampton A. Escape from the Laboratory: Ethnographic Methods in the Study of Elder and Family Court Mediation. Negotiation Journal. 2016; 32 (3): 191-211.

[12] Smith M, Leigh B. Virtual subjects: Using the Internet as an alternative source of subjects and research environment. Behavior Research Methods, Instruments, \& Computers. 1997; 29 (4): 496-505.

[13] Robinson K. Unsolicited Narratives from the Internet: A Rich Source of Qualitative Data. Qualitative Health Research. 2001; 11 (5): 706-714.

[14] Prior D, Miller L. Webethnography: Towards a Typology for Quality in Research Design. International Journal of Market Research. 2012; 54 (4): 503-520.

[15] Holt T, Freilich J, Chermak S. Internet-Based Radicalization as Enculturation to Violent Deviant Subcultures. Deviant Behavior. 2016; 38 (8): 855-869.

[16] Koehler D. The Radical Online: Individual Radicalization Processes and the Role of the Internet. Journal for Deradicalization. 2014; 15 (1): 116-134.

[17] Hetland P, Morch AI. Ethnography for Investigating the Internet. Seminar.net - International journal of media, technology and lifelong learning. 2016; 12 (1): 1-14.

[18] Yap A. Ad Hominem Fallacies, Bias, and Testimony. Argumentation. 2012; 27 (2): 97-109.

[19] Frans H. van Eemeren, Bart Garssen, and Bert Meuffels. The disguised abusive ad hominem empirically investigated: Strategic maneuverings with direct personal attacks. Thinking \& Reasoning. 2012; 18 (3): 344-364.

[20] Hansen HV. The Straw Thing of Fallacy Theory: The Standard Definition of 'Fallacy'. Argumentation, 2002; 16: 133-155.

[21] Brisson J, Markovits H, Robert S, Schaeken W. Reasoning from an incompatibility: False dilemma fallacies and content effects. Memory \& Cognition. 2018; 46 (5): 657-670.

[22] Noles N. Salience or centrality: Why do some features influence inductive generalization more than others? Developmental Psychology. 2019; 55 (3): 612-622.

[23] Chambers J, Melnyk D. Why Do I Hate Thee? Conflict Misperceptions and Intergroup Mistrust. Personality and Social Psychology Bulletin. 2006; 32 (10): 1295-1311.

[24] Renkema L, Stapel D, Maringer M, van Yperen N. Terror Management and Stereotyping: Why Do People Stereotype When Mortality Is Salient?. Personality and Social Psychology Bulletin. 2008; 34 (4): 553-564.

[25] Merriam-Webster Dictionary Online. Definition of Charisma [Internet]. Merriam-webster.com. 2019 [cited 16 July 2019]. Available https://www.merriam-webster.com/dictionary/charisma.

[26] Jegan V. Interfering with Democracy: The Coalition between right-wing extremism and terrorism inside a globalized World. Research and Science Today. 2016; 12: 69-77.

[27] Collins Dictionary Online. Ideology definition and meaning | Collins English Dictionary [Internet]. Collinsdictionary.com. 2019 [cited 17 July 2019]. Available from: https://www.collinsdictionary.com/dictionary/english/ideology 
[28] Freeman M. A Theory of terrorist leadership (and its consequences for leadership targeting). Terrorism and Political Violence. 2014; 26 (4): 666-687.

[29] Machnikowski R. Terrorist Leadership - to Kill or Not to Kill. Polish Quarterly of International Affairs, 2013; 22, (1): 49-51.

[30] Alley C. Are autistic people at greater risk of being radicalised? [Internet]. The Conversation. 2019 [cited 17 July 2019]. Available

from: http://theconversation.com/are-autistic-people-at-greater-riskof-being-radicalised-76726.

[31] Corner E, Gill P, Mason O. Mental health disorders and the terrorist: A research note probing selection effects and disorder prevalence. Studies in Conflict \& Terrorism, 2016; 39 (6): 560-568.

[32] Palermo M. Developmental Disorders and Political Extremism: A Case Study of Asperger Syndrome and the Neo-Nazi Subculture. Journal of Forensic Psychology Practice. 2013;13 (4): 341-354.

[33] Faccini L, Allely C. Rare instances of individuals with autism supporting or engaging in terrorism. Journal of Intellectual Disabilities and Offending Behaviour. 2017; 8 (2): 70-82.

[34] Bhui K, Everitt B, Jones E. Might Depression, Psychosocial Adversity, and Limited Social Assets Explain Vulnerability to and Resistance against Violent Radicalisation?. PLoS ONE. 2014; 9 (9): e105918.

[35] Palermo MT. Developmental Disorders and Political Extremism: A Case Study of Asperger Syndrome and the Neo-Nazi Subculture. Journal of Forensic Psychology Practice. 2013; 13: 341-354.

[36] Milla M, Faturochman, Ancok D. The impact of leader-follower interactions on the radicalization of terrorists: A case study of the Bali bombers. Asian Journal of Social Psychology. 2013; 16 (2): 92-100.

[37] Shapiro L, Maras M. Women's Radicalization to Religious Terrorism: An Examination of ISIS Cases in the United States. Studies in Conflict \& Terrorism. 2018; 42 (1-2): 88-119.

[38] Lucy Fisher P. Children and teenagers groomed for radicalisation by far-right [Internet]. Thetimes.co.uk. 2019 [cited 19 July 2019]. Available from: https://www.thetimes.co.uk/article/children-and-teenagers-gro omed-for-radicalisation-by-far-right-9q8w65rnw.

[39] Morris E. Children: extremism and online radicalization. Journal of Children and Media. 2016; 10 (4): 508-514.

[40] Rapaport W J. William Perry's scheme of intellectual and ethical development. [Internet]. Cse.buffalo.edu. 2019 [cited 20 July 2019]. Available from: https://cse.buffalo.edu/ rapaport/perry.positions.html.

[41] Rapaport W J. Critical Thinking and Cognitive Development. American Philosophical Association Newsletter on Pre-College Instruction in Philosophy 1 (Spring/Summer 1984) 4-5. Reprinted in Proceedings of the American Philosophical Association. 1984; 57: 610-615. [41].

[42] Lazzari C, Rabottini M. Psychiatry of the radicalizing family. European Psychiatry. 2019; 56 (Supplement1): E-PV0370.
[43] Lazzari C, Rabottini M. Psychiatry of radicalization and terrorism. European Psychiatry. 2019; 56 (Supplement1): E-PP0560.

[44] Schlee M. Radicalized children pose security 'risk' in Germany: report [Internet]. Politico. 2019 [cited 20 July 2019]. Available from:

https://www.politico.eu/article/radicalization-islamic-state-terror ism-radicalized-children-pose-security-risk-in-germany-report/].

[45] Solfrini F. Disarming evil, the Italian initiatives in preventing radicalization-Mediterranean Affairs [Internet]. Mediterranean Affairs. 2019 [cited 20 July 2019]. Available from: http://mediterraneanaffairs.com/disarming-evil-italian-initiativ es-preventing-radicalization/.

[46] National Society for the Prevention of Cruelty to Children. Protecting children from radicalisation [Internet]. NSPCC. 2019 [cited 20 July 2019]. Available from: https://www.nspcc.org.uk/what-you-can-do/report-abuse/dedic ated-helplines/protecting-children-from-radicalisation/.

[47] Silas D. Boko Haram: Nigerian Army hands over 183 radicalized children to UN - Daily Post Nigeria [Internet]. Daily Post Nigeria. 2019 [cited 20 July 2019]. Available from: http://dailypost.ng/2018/07/09/boko-haram-nigerian-army-han ds-183-radicalized-children-un/.

[48] Johnson: Remove radical risk children [Internet]. BBC News. 2019 [cited 20 July 2019]. Available from: https://www.bbc.co.uk/news/uk-26413024.

[49] Mukhopadhyay S. Five Steps to Protect Children from Radicalization [Internet]. International Business Times. 2019 [cited 20 July 2019]. Available from: https://www.ibtimes.com/five-steps-protect-children-radicaliz ation-1917930.

[50] Weale S. Nursery staff urged to look for signs of radicalisation [Internet]. The Guardian. 2019 [cited 22 July 2019]. Available from: https://www.theguardian.com/uk-news/2016/jan/05/nursery-staff-ra dicalisation-children-parents.

[51] 10. Quinn B. Nursery 'raised fears of radicalisation over boy's cucumber drawing' [Internet]. the Guardian. 2019 [cited 22 July 2019]. Available from: https://www.theguardian.com/uk-news/2016/mar/11/nursery-r adicalisation-fears-boys-cucumber-drawing-cooker-bomb.

[52] Hope C, Swinford S. Isil schoolgirl Shamima Begum 'will not be rescued', as Security Minister warns 'actions have consequences' [Internet]. The Telegraph. 2019 [cited 22 July 2019]. Available from: https://www.telegraph.co.uk/politics/2019/02/14/isil-schoolgir 1-shamima-begum-now-wants-come-home-faces-prosecution/.

[53] Steafel E. How Shamima Begum and two other schoolgirls from Bethnal Green became Isil brides [Internet]. The Telegraph. 2019 [cited 22 July 2019]. Available from: https://www.telegraph.co.uk/news/2019/02/14/british-schoolgi rl-says-doesnt-regret-four-years-living-isil/.

[54] Morgades-Bamba C, Raynal P, Chabrol H. Exploring the Radicalization Process in Young Women. Terrorism and Political Violence. 2018; 1-19.

[55] Pearson E, Winterbotham E. Women, Gender and Daesh Radicalisation. The RUSI Journal. 2017; 162 (3): 60-72. 